\title{
Reading aloud polysyllabic words and nonwords: The syllabic length effect reexamined
}

\author{
LUDOVIC FERRAND \\ C.N.R.S. and Université René Descartes, Paris, France
}

\begin{abstract}
Two experiments were run in order to reinvestigate the role of the number of syllables in naming. Experiment 1 (word naming) showed that effects of number of syllables on naming latency were observed for very low-frequency words but not for high-frequency words (thus replicating Jared \& Seidenberg's, 1990, finding). In Experiment 2 (nonword naming), syllabic length effects were also obtained for nonwords. Control experiments found no effect on the latency of delayed naming of the same words and nonwords. These results suggest that naming does require syllabic decomposition, at least for very low-frequency words and nonwords in French. In particular, these data are compatible with any model of reading that postulates that reading aloud depends on the activity of two procedures: (1) a procedure that operates in parallel across a letter string (and does not generate a strong syllabic length effect) and that is the predominant process in generating responses to high-frequency words, and (2) another procedure that operates serially across a letter string (and generates a strong syllabic length effect) and that is the predominant process in generating responses to very low-frequency words and nonwords. These results are discussed in the context of the multiple-trace memory model for polysyllabic word naming (Ans, Carbonnel, \& Valdois, 1998).
\end{abstract}

Many studies have examined whether the number of syllables in a word is related to naming latencies, but these studies have yielded inconsistent results (see Henderson, 1982, for a review). In their seminal study, Eriksen, Pollack, and Montague (1970) presented subjects with monosyllabic and trisyllabic words that were matched so that each monosyllabic word was the first syllable in a trisyllabic word (e.g., cab/cabinet). They found a significant effect of number of syllables on naming latency. However, the number of syllables was confounded with word length. In a later study, Klapp, Anderson, and Berrian (1973) found a significant effect of number of syllables when number of letters was constant. In the present context, it is worth noting that Klapp's evidence comes also from picture naming and Arabic numeral naming (see Klapp \& Wyatt, 1976, for a review of their work). Klapp et al. argued that the syllabic length effect was due not to visual input process but to the preparation of the articulatory response. This effect could not have been due to a difference in word perception times since the difference disappeared in a semantic categorization task where no articulation is required. Using a delayed naming task, Klapp et al. found no difference in naming latency between one- and two-syllable words, suggesting that the syllabic

\footnotetext{
The author is grateful to Ken Forster, Debra Jared, Keith Rayner, and an anonymous reviewer for helpful feedback on an earlier version of this manuscript. Thanks are extended to Pascale Colé for her invaluable help in analyzing morphologically complex words and to Véronique Pinaud for running the experiments. Correspondence should be addressed to L. Ferrand, C.N.R.S. and Université René Descartes, Laboratoire de Psychologie Expérimentale, 71 Av. Edouard Vaillant, 92774 Boulogne Billancourt Cedex, France (e-mail: ferrand@psycho.univ-paris5.fr).
}

length effect is a phonological encoding effect, not an articulatory effect. In a subsequent study, Klapp and Erwin (1976) measured the durations of the one- and two-syllable words of the 1973 study. They found no difference, suggesting that response duration cannot have been the cause of the syllabic length effect.

Despite these positive findings, other studies have reported no effect of the number of syllables on the initiation of word naming (e.g., Forster \& Chambers, 1973; Frederiksen \& Kroll, 1976; Mason, 1978; Richardson, 1976). More recent research conducted by Jared and Seidenberg (1990) indicates, however, a possible source of discrepancy between the results mentioned above. According to Jared and Seidenberg, studies examining the effects of number of syllables on naming have yielded inconsistent results because none of these studies examined the interaction of word frequency and number of syllables on naming. In their Experiment 3, Jared and Seidenberg showed that the number of syllables in a word influenced naming latencies only for low-frequency words. The authors interpreted this syllabic effect within the framework of the parallel distributed processing (PDP) model developed by Seidenberg and McClelland (1989). According to Jared and Seidenberg, an effect of number of syllables in naming does not necessarily mean that words are decomposed into syllables. The PDP model was used to describe how one might get syllable effects without explicit syllable units. They suggested that syllable effects might actually be spelling-sound consistency effects. Because each syllable must have a vowel, words with a greater number of syllables also have a greater number of vowels. In English (contrary to French), vowels are the greatest source of spelling-sound inconsistency (see Ziegler, 
Jacobs, \& Stone, 1996; Ziegler, Stone, \& Jacobs, 1997). So words with more vowels have more sources of inconsistency than words with the same number of letters but fewer vowels. High-frequency words may not show a syllable effect either because the effects are attenuated by frequent exposure to the word or because the highfrequency words have less inconsistent vowels than the low-frequency words used in the Jared and Seidenberg study.

The syllabic length effect constitutes an interesting challenge for current models of word naming. In principle, the dual-route theory of word naming (Coltheart, 1978; Coltheart, Curtis, Atkins, \& Haller, 1993) should be able to explain the syllabic length effect with minor modifications. Traditional dual-route theory (Coltheart, 1978 ) assumes that normal readers have two methods at their disposal for converting print into speech: a lexical route and a nonlexical route. For the lexical route, words are represented in an orthographic input lexicon and are read aloud by retrieving the word's pronunciation. The nonlexical route converts the graphemic representation of a letter string into phonemes piece by piece. In other words, the lexical route processes letter strings in parallel, whereas the nonlexical route processes letter strings sequentially. The grapheme-phoneme conversion approach may have been motivated by properties of the English language. In English, syllabification of words is quite complex, while the resulting syllables show little consistency with respect to their phonological interpretation. Therefore, this theory has perhaps chosen to bypass the explicit use of syllables and assumes that groups of graphemes from the visual input trigger conversion rules (Coltheart, 1978). However, if we consider English words with clear syllable boundaries (such as divorce) or French words (i.e., French is usually described as a syllabletimed language having clear syllable boundaries; see Ferrand, Segui, \& Grainger, 1996), and if we replace phonemes with syllables when polysyllabic word naming is considered, then the dual-route model could easily explain the syllabic length effect. One reason why number of syllables might affect human naming latency, compatible with the dual-route theory, is that the number of syllables reflect the operation of a sequential reading mechanism. A sequential reading mechanism will show an effect of number of syllables because the more syllables there are to process, the longer it will take to generate the phonological code for the letter string. The dual-route theory predicts that the number of syllables will affect naming latency for nonwords and (very) low-frequency words more than for high-frequency words. This is because nonwords and (very) low-frequency words are read via a lengthsensitive nonlexical mechanism.

Recently, Ans, Carbonnel, and Valdois (1998) proposed a connectionist multiple-trace memory (MTM) model explicitly devoted to polysyllabic word naming. This model is related on some specific aspects to both the dual-route model (Coltheart et al., 1993) and the PDP model (Sei- denberg \& McClelland, 1989) but is unique in a number of respects. In contrast to the PDP model, it does not postulate that a single uniform procedure is used for generating the pronunciation of both words and nonwords. Rather, it is assumed that two types of procedures, a global and an analytic one, are required for processing all kinds of letter strings. However, it cannot be viewed as simply another version of the dual-route model since the global and analytic procedures do not work in parallel: Global processing always proceeds first, the analytic procedure applying only secondarily when global processing has failed. And, contrary to the dual-route model, this model does not retain the assumption that knowledge about spelling-to-sound correspondences is represented in terms of orthography-tophonology conversion rules and that the pronunciation of nonwords is generated by application of these rules. Rather, and more in line with the PDP model, it assumes that mapping from orthography to phonology emerges only from the integrated activation of previously experienced whole words and word syllabic segments. An interesting property of the model is that it contains explicit syllable units. This model predicts that naming latencies should be longer for analytically processed printed stimuli than for globally processed printed stimuli since the analytic mode applies only after the global mode has failed. Therefore, an increase in naming latencies with syllabic length is predicted for nonwords since analytic processing is sequential, each syllable requiring a new visual capture of information. The MTM model also predicts a syllabic length effect for very low-frequency words since the analytic process applies to these words.

The aim of the present study was to reexamine whether there are equivalent or differential effects of number of syllables on the latency to name high-frequency words, low-frequency words, and nonwords in French. The first experiment was a replication of Jared and Seidenberg's (1990) study but with better controls in terms of initial syllable (items matched on the first syllable were used since Carreiras, Alvarez, \& De Vega, 1993, found a syllable frequency effect on the initial syllable on naming), number of orthographic neighbors (hermits were used; i.e., words with no orthographic neighbors; Grainger, 1990) and syllabification (French words with clear syllable boundaries were used). Furthermore, in order to rule out the possibility that the syllabic length effect is due to ease of articulation rather than the time taken to generate a phonological code, we conducted a control delayed naming task. In the second experiment, nonwords were used instead of words.

\section{EXPERIMENT 1}

\section{Method}

Subjects. Fifty-four psychology students at René Descartes University, Paris, participated in the experiment for course credit: 34 in the immediate naming task and 20 in the delayed naming task. All were native speakers of French and had normal or corrected-to-normal vision. 
Table 1

Stimulus Characteristics of Words Used in Experiment 1

\begin{tabular}{|c|c|c|c|c|c|c|c|c|c|}
\hline \multirow[b]{2}{*}{ Word Type } & \multirow[b]{2}{*}{ Letters } & \multirow[b]{2}{*}{ Neighbors } & \multicolumn{3}{|c|}{ Frequency } & \multicolumn{2}{|c|}{ Phonemes } & \multicolumn{2}{|c|}{$\begin{array}{c}\text { Bigram } \\
\text { Frequency }\end{array}$} \\
\hline & & & $M$ & $S D$ & Range & $M$ & $S D$ & $M$ & $S D$ \\
\hline \multicolumn{10}{|c|}{ High-Frequency Words } \\
\hline Two syllables & 8 & 0 & 34.12 & 21 & $11.5-90.7$ & 5.75 & 0.55 & 2.82 & 0.27 \\
\hline Three syllables & 8 & 0 & 34.74 & 23 & $10.3-103.8$ & 6.65 & 0.67 & 2.84 & 0.12 \\
\hline \multicolumn{10}{|c|}{ Low-Frequency Words } \\
\hline Two syllables & 8 & 0 & 2.94 & 2.8 & $0.08-7.87$ & 5.60 & 0.69 & 2.76 & 0.27 \\
\hline Three syllables & 8 & 0 & 2.33 & 2.5 & $0.1-7.95$ & 6.65 & 0.58 & 2.74 & 0.22 \\
\hline
\end{tabular}

Stimuli and Design. The stimuli were 80 French words: 40 high-frequency items and 40 very low-frequency items. Half of the words had two syllables, and the remaining half had three syllables. Thus, the design included two factors: frequency (high or low) and number of syliables (two or three). As can be seen in Table 1, words were matched for a number of variables: word frequency, bigram frequency, number of letters, number of phonemes, and number of orthographic neighbors. Word frequencies were estimated according to a French frequency count described in Content, Mousty, and Radeau (1990). Words in the four groups were also matched for initial phoneme and initial syllable. A complete list of the stimuli is presented in Appendix A.

Procedure. The stimuli were displayed in lowercase letters in the center of a video monitor connected to a computer. In the immediate naming task, words were presented one at a time and remained on the screen until the subject began to speak into a microphone connected to a voice-operated relay that was connected to the computer. The real-time clock in the computer timed the response latencies in milliseconds from the appearance of the stimulus to the onset of the subject's response. The intertrial interval was $2 \mathrm{sec}$. The delayed naming task was identical to the immediate naming task except that the subjects waited until the appearance of a response cue (a row of five stars) before pronouncing the letter string as quickly as possible. The response cue was displayed $2 \mathrm{sec}$ after the disappearance of the to-be-named stimulus. Latencies in this case were measured from the appearance of the response cue until the triggering of the voice key. The experimenter recorded mispronunciation errors by hand. The subjects were first shown 10 practice words and then the 80 experimental words. Items were presented in random order.

\section{Results}

The mean naming times and percentages of errors are presented in Table 2 for the immediate and delayed nam- ing task. Latencies longer than $1,500 \mathrm{msec}$ were excluded (less than $1 \%$ of the data). There were two factors in the analyses of variance (ANOVAs): frequency (high or low) and number of syllables (two or three). The $F$ values are reported by subjects $(F 1)$ and by items $(F 2)$.

Immediate naming task. There was a main effect of frequency: The subjects took longer to name lowfrequency words $(552 \mathrm{msec})$ than high-frequency words $(522 \mathrm{msec})[F 1(1,33)=95.06, p<.001 ; F 2(1,76)=$ $50.08, p<.001]$. There was also a main effect of number of syllables, with the subjects naming words with two syllables $(530 \mathrm{msec})$ more quickly than those with three syllables $(545 \mathrm{msec})[F 1(1,33)=23.58, p<.001$; $F 2(1,76)=11.56, p<.005]$. More interesting, the interaction between frequency and number of syllables was also significant $[F 1(1,33)=9.98, p<.01 ; F 2(1,76)=5.03$, $p<.025]$. Planned comparisons show that the syllabic effect was significant for low-frequency words $[F 1(1,33)=$ $25.40, p<.001 ; F 2(1,38)=13.34, p<.001$ ] but not for high-frequency words $[F 1(1,33)=1.20 ; F 2(1,38)=0.77]$. In the error data, there were no main or interaction effects $(\text { all } F \mathrm{~s}<1)^{1}$.

Delayed naming task. An ANOVA conducted on naming latencies and error data showed no main or interaction effects (all $F$ s $<1$ ).

\section{Discussion}

The results indicate an interaction between frequency and number of syllables in the immediate naming task. More specifically, the number of syllables in a word in-

Table 2

Mean Naming Latencies (in Milliseconds), Standard Deviations, and Percentage of Errors in Experiment 1 (Immediate and Delayed Word Naming)

\begin{tabular}{|c|c|c|c|c|c|c|c|}
\hline \multirow[b]{2}{*}{ Word Type } & \multicolumn{3}{|c|}{ High-Frequency Words } & \multicolumn{3}{|c|}{ Low-Frequency Words } & \multirow[b]{2}{*}{$M$} \\
\hline & $M$ & $S D$ & $\%$ Errors & $M$ & $S D$ & $\%$ Error & \\
\hline \multicolumn{8}{|c|}{ Immediate Naming } \\
\hline Two syllables & 520 & 73 & 1.9 & 540 & 80 & 3.6 & 530 \\
\hline Three syllables & 524 & 78 & 2.6 & 564 & 76 & 3.6 & 545 \\
\hline$M$ & 522 & & & 552 & & & \\
\hline \multicolumn{8}{|c|}{ Delayed Naming } \\
\hline Two syllables & 328 & 32 & 0.5 & 332 & 38 & 0.9 & 329 \\
\hline Three syllables & 330 & 35 & 0.9 & 335 & 40 & 0.6 & 332.5 \\
\hline$M$ & 329 & & & 333.5 & & & \\
\hline
\end{tabular}


Table 3

Mean Naming Latencies (in Milliseconds), Standard Deviations, and Percentage of Errors in Experiment 2 (Immediate and Delayed Nonword Naming)

\begin{tabular}{lccccccc}
\hline & \multicolumn{3}{c}{ Immediate Naming } & & \multicolumn{3}{c}{ Delayed Naming } \\
\cline { 2 - 4 } \cline { 6 - 8 } Nonword Type & $M$ & $S D$ & $\%$ Errors & & $M$ & $S D$ & \% Errors \\
\hline Two syllables & 651 & 102 & 3.0 & & 433 & 54 & 1.0 \\
Three syllables & 686 & 108 & 5.1 & & 435 & 59 & 1.0 \\
Difference & +35 & +2.1 & +2 & & & 0 \\
\hline
\end{tabular}

fluenced naming latencies only for low-frequency words. This is a perfect replication of the results obtained by Jared and Seidenberg (1990) in English. It is important to note that these results were not due to differences between items in number of letters, number of phonemes, number of orthographic neighbors, bigram frequency, initial phoneme, and initial syllable. Furthermore, there were no effects of number of syllables and of frequency in a control delayed naming task. It was assumed that if the delay was long enough, the word would have been recognized and the articulatory motor program assembled and stored in a buffer. On presentation of the cue, the subject would retrieve and execute this motor program. Any remaining effect of number of syllables (and of frequency), then, would have to be attributed to the stage of response execution. Since there was no difference in naming latency between two-syllable words and three-syllable words, the syllabic length effect is a real phonological encoding effect, not an articulatory effect.

\section{EXPERIMENT 2}

In Experiment 2, subjects had to read aloud nonwords instead of words. According to the MTM model (Ans et al., 1998) and the DRC model (Coltheart et al., 1993), nonwords should show a larger effect of syllable length than should words.

\section{Method}

Subjects. Forty additional psychology students at René Descartes University, Paris, participated in the experiment for course credit: 20 in the immediate naming task and 20 in the delayed naming task. All were native speakers of French and had normal or corrected-to-normal vision. None had participated in Experiment 1 .

Stimuli and Design. The stimuli were 120 nonwords: 60 bisyllabic items and 60 trisyllabic items. The nonwords were generated from French words by replacing a consonant with another consonant or a vowel with another vowel. All the nonword stimuli had straightforward, unambiguous pronunciations following standard French spelling-to-sound translation rules. To evaluate the nonwords, 10 judges were asked to read them aloud. Any alternative pronunciation was considered as an error. For an item to be selected as a legal nonword, 9 of the judges must have pronounced it as following standard French spelling-to-sound translation rules. Again, nonword stimuli were matched for number of letters $(n=8)$, number of phonemes $(n=6-7)$, number of orthographic neighbors ( $n=1$; it corresponds to the base word from which the nonword was derived), ini- tial phoneme, and initial syllable. A complete list of the stimuli is presented in Appendix B.

Procedure. Exactly the same procedure as that in Experiment 1 was used, except that the subjects were instructed to read aloud nonword stimuli.

\section{Results}

The mean naming times and percentages of errors are presented in Table 3 for the immediate and delayed naming task. Latencies longer than $1,500 \mathrm{msec}$ were excluded (less than $1 \%$ of the data). The $t$ values are reported by subjects $(t 1)$ and by items $(t 2)$.

Immediate naming task. There was a significant effect of number of syllables, with the subjects naming nonwords with two syllables $(65 \mathrm{l} \mathrm{msec})$ more quickly than those with three syllables $(686 \mathrm{msec})[t 1(19)=7.8, p<$ $.001 ; t 2(118)=3.44, p<.005]$. In the error data, there was also an effect of number of syllables $[t 1(19)=2.15, p<$ $.04 ; t 2(118)=1.69, p<.05$ ].

Delayed naming task. An ANOVA conducted on naming latencies and error data showed no main or interaction effects (all $t \mathrm{~s}<1$ ).

\section{GENERAL DISCUSSION}

The results from this study extend those of previous studies by showing that there are differential effects of number of syllables on word and nonword naming latency. In Experiment 1, number of syllables had an effect only on low-frequency words (thus replicating Jared \& Seidenberg's, 1990, result). However, there was no effect of number of syllables for high-frequency words. In Experiment 2 , the syllabic length effect was also observed with nonword stimuli. This effect was observed when items were matched for number of letters, number of phonemes, number of orthographic neighbors, bigram frequency, initial phoneme, and initial syllable.

The present study differed from Jared and Seidenberg's (1990) study on a number of points. First, it was conducted in French, which is usually described as a syllabletimed language having clear syllabic boundaries (Cutler, Mehler, Norris, \& Segui, 1986; Segui, 1984), contrary to English, which is described as a language having unclear syllable boundaries (Ferrand, Segui, \& Humphreys, 1997). Second, I used a delayed naming control procedure to ensure that the syllable length effects were not due to articulatory factors. Third, the syllable length effect was extended to nonword naming.

Some recent studies have investigated the length effect in word and nonword reading aloud in order to assess whether the effect was driven by the number of letters in a string or by the number of phonemes in a string (Rastle \& Coltheart, 1998; Weekes, 1997). It is important to note at this point that our syllabic length effects were not confounded with the number of letters since all the stimuli had the same number of letters. It could be argued that our syllabic effects were confounded with the number of 
phonemes since three-syllable words had, on average, one more phoneme than two-syllable words (see Table 1). However, Rastle and Coltheart (1998) recently showed that there was a disadvantage for five-letter stimuli having three phonemes, relative to five-letter stimuli having five phonemes. If anything, the phoneme length effect is facilitatory, and it cannot explain our syllabic length effect which is slowing down naming latencies.

The results reported here are compatible with any model of reading aloud that translates orthography to phonology via two procedures: (1) a lexical procedure that operates in parallel across the input screen (and does not generate a strong syllabic length effect) and that is the predominant process in generating responses to high-frequency words, and (2) a nonlexical procedure that operates serially from left to right across the string (and generates a strong syllabic length effect) and that is the predominant process in generating responses to low-frequency words and nonwords.

There is one model that could offer a coherent explanation of the present results. The MTM model (presented in the introduction) is a model developed explicitly for polysyllabic word naming (Ans et al., 1998). This model postulates the existence of two reading procedures: a global procedure using knowledge about whole word correspondences, and an analytic procedure based on the activation of word syllabic segments. However, these two procedures do not work in parallel: Global processing always proceeds first, the analytic procedure applying only secondarily when global processing has failed. Since the global procedure always proceeds first, the analytic procedure being used only after global processing has failed, the MTM model predicts that naming latencies of all words would be systematically shorter than the naming latencies of any nonwords. More specifically, an increase in naming latencies with syllabic length is predicted for nonwords and very low-frequency words since they are processed analytically. In the MTM model (Ans et al., 1998), $97.52 \%$ of the words (on 12,839 words) were processed globally; the remaining ( $n=326 ; 2.48 \%)$ were processed in the analytic mode. According to Ans et al., analytic processing essentially applies to words of the lowest frequency (median $=1.31$ occurrence per million; range $=0.04-5.36$ occurrences per million), the probability that a word will be processed globally increasing with its frequency. In Experiment 1, our very low-frequency words had, on average, 2.63 occurrences per million (range $=0.08-7.95$ ), so it seems probable that these words would be processed analytically in the model. Concerning nonwords, $22.65 \%$ were processed globally (out of 830 nonwords), although most were read analytically $(77.35 \% ; n=642)$. Ans et al. showed that the probability that a nonword would be processed globally increased with its number of neighbors. More specifically, they showed that nonwords with a single neighbor were mainly processed analytically (it was the case for $68 \%$ of their nonwords). Therefore, since, in our Experiment 2, our nonwords had only one orthographic neighbor (corresponding to the base word from which they were derived), it seems reasonable to suggest that most of our nonwords were processed analytically.

A modified version of the dual-route model (Coltheart, 1978; Coltheart et al., 1993), in which the nonlexical route would operate at the syllabic level rather than at the phoneme level, also offers a potential explanation of the present results. In this modified model, syllabic length effects on naming latency would reflect the serial operation of the nonlexical route. Because the lexical route processes high-frequency words so quickly, the nonlexical route makes no contribution to the naming of these words. When the stimulus is a very low-frequency word, however, lexical processing is sufficiently slow to allow a substantial contribution from the nonlexical route. When the stimulus is a nonword, the nonlexical route is the major determinant of pronunciation, since nonwords cannot be pronounced correctly via the lexical route. It follows that the syllabic length effect should be nonexistent for high-frequency words, but strong for very low-frequency words, and even stronger for nonwords. This is exactly the pattern of results we obtained. Therefore, a slightly modified version of the dual-route model that incorporates syllabic units instead of phonemic units offers a coherent explanation of the present results. The effect of number of syllables on very low-frequency word naming and nonword naming can be accounted for by the sequential operation of the nonlexical route in the dual-route model.

In the present experiments, words and nonwords were not presented in a mixed list, so the subjects knew whether an item would be a word or a nonword prior to presentation. Under these conditions, use of the nonlexical route may have been maximized in Experiment 2 (nonwords only) but minimized in Experiment 1 (words only), and use of the lexical route may have been minimized in Experiment 2 and maximized in Experiment 1. Despite this, the syllabic length effect was observed in Experiment 1 (words only) for very low-frequency words. It is also possible that the effect was slightly overestimated for nonwords (since these items were blocked in Experiment 2).

Our finding that the number of syllables has a clear effect on naming latencies for very low-frequency words and for nonwords but not for high-frequency words supports models of naming that assume that a sequential process can be used to read aloud (Ans et al., 1998; Coltheart, 1978; Coltheart et al., 1993).

\section{REFERENCES}

Ans, B., Carbonnel, S., \& Valdois, S. (1998). A connectionist multipletrace memory model for polysyllabic word reading. Psychological Review, 105, 678-723.

Carreiras, M., Alvarez, C. J., \& De Vega, M. (1993). Syllable frequency and visual word recognition in Spanish. Journal of Memory \& Language, 32, 766-780.

ColtheART, M. (1978). Lexical access in simple reading tasks. In G. Underwood (Ed.), Strategies of information processing (pp. 151216). London: Academic Press. 
Coltheart, M., Curtis, B., Atkins, P., \& Haller, M. (1993). Models of reading aloud: Dual-route and parallel-processing-distributed approaches. Psychological Review, 100, 589-608.

Content, A., Mousty, P., \& Radeau, M. (1990). Brulex: Une base de données lexicales informatisée pour le Français écrit et parlé [Brulex: A lexical database for written and spoken French]. L'Année Psychologique, 90, 551-566.

Cutler, A., Mehler, J., Norris, D., \& Segui, J. (1986). The syllable's differing role in the segmentation of French and English. Journal of Memory \& Language, 25, 385-400

Eriksen, C. W., Pollack, M. D., \& Montague, W. E. (1970). Implicit speech: Mechanism in perceptual coding? Journal of Experimental Psychology, 84, 502-507.

Ferrand, L., Segui, J., \& Grainger, J. (1996). Masked priming of word and picture naming: The role of syllabic units. Journal of Memory \& Language, 35, 708-723.

Ferrand, L., Segui, J., \& Humphreys, G. W. (1997). The syllable's role in word naming. Memory \& Cognition, 25, 458-470

Forster, K. I., \& Chambers, S. (1973). Lexical access and naming time. Journal of Verbal Learning \& Verbal Behavior, 12, 627-635.

Frederiksen, J. R., \& Kroll, J. F. (1976). Spelling and sound: Approaches to the internal lexicon. Journal of Experimental Psychology: Human Perception \& Performance, 2, 361-379.

Grainger, J. (1990). Word frequency and neighborhood frequency effects in lexical decision and naming. Journal of Memory \& Language, 29, 228-244.

HENDERSON, L. (1982). Orthography and word recognition in reading London: Academic Press.

JARED, D., \& SEIDENBERG, M. S. (1990). Naming multisyllabic words Journal of Experimental Psychology: Human Perception \& Performance, 16, 92-105.

Klapp, S. T., Anderson, W. G., \& Berrian, R. W. (1973). Implicit speech in reading reconsidered. Journal of Experimental Psychology, 100, 368-374.

KLAPP, S. T., \& ERWIN, C. I. (1976). Relation between programming time and duration of the response being programmed. Journal of $E x$ perimental Psychology: Human Perception \& Performance, 2, 591 598

KLAPP, S. T., \& WYATT, E. T. (1976). Motor programming within a sequence of responses. Journal of Motor Behavior, 8, 19-26.

MASON, M. (1978). From print to sound in mature readers as a function of reader ability and two forms of orthographic regularity. Memory \& Cognition, 6, 568-581.

Rastle, K., \& Coltheart, M. (1998). Whammies and double whammies: The effect of length on nonword reading. Psvchonomic Bulletin \& Review, 5, 277-282.
RichaRDSON, J. T. E. (1976). The effect of stimulus attributes upon latency of word recognition. British Journal of Psychology, 67, 315-325.

SEgui, J. (1984). The syllable: A basic perceptual unit in speech perception? In H. Bouma \& D. G. Bouwhuis (Eds.), Attention and performance X: Control of language processes (pp. 165-181). Hillsdale, NJ: Erlbaum.

SeidenberG, M. S., \& McClelland, J. L. (1989). A distributed, developmental model of visual word recognition and naming. Psychological Review, 96, 523-568.

WEEKES, B. S. (1997). Differential effects of number of letters on word and nonword naming latency. Quarterly Journal of Experimental Psychology, 50A, 439-456.

Ziegler, J. C., JACOBS, A. M., \& STONE, G. O. (1996). Statistical analysis of the bidirectional inconsistency of spelling and sound in French Behavior Research Methods, Instruments, \& Computers, 28, 504 515.

Ziegler, J. C., Stone, G. O., \& JACOBS, A. M. (1997). What is the pronunciation for -ough and the spelling for $/ \mathrm{u} /$ ? A database for computing feedforward and feedback inconsistency in English. Behavior Research Methods, Instruments, \& Computers, 29, 600-618.

\section{NOTE}

1. One reviewer suggested that, because some of our stimuli were morphologically complex words, naming times might be influenced not just by the surface frequency of the word itself but also by the frequency of all the inflected variations of it. In order to check this possibility, I did post hoc analyses contrasting monomorphemic words (6 in each condition out of 20 per condition) and polymorphemic words ( 10 in each condition out of 20 ). These post hoc analyses showed exactly the same pattern of results for monomorphemic and polymorphemic words. There was a main effect of frequency for monomorphemic words $[F 2(1,20)=22.30, p<.001]$ and for polymorphemic words $[F 2(1,36)=14.60, p<.01]$. There was also a main effect of number of syllables, with the subjects naming words with two syllables more quickly than those with three syllables: This was the case for monomorphemic words $[F 2(1,20)=4.09, p<.05]$ and for polymorphemic words $[F 2(1,36)=8.29, p<.01]$. More interesting, the interaction between frequency and number of syllables was also significant for monomorphemic words $[F 2(1,20)=5.19, p<.05]$ and for polymorphemic words $[F 2(1,36)=6.78, p<.02]$. Planned comparisons show that the syllabic effect was significant for low-frequency words [for monomorphemic words, $F 2(1,10)=12.32, p<.01$; for polymorphemic words, $F 2(1,18)=12.14, p<.01]$ but not for high-frequency words [for monomorphemic words, $F 2(1,10)<1$; for polymorphemic words, $F 2(1,18)<1]$

\section{APPENDIX A \\ Items Used In Experiment 1}

Items are listed in the following order: high-frequency bisyllabic, high-frequency trisyllabic, low-frequency bisyllabic, low-frequency trisyllabic.

bataille, balancer, barrette, barillet; commande, colonial, copieuse, communal; conclure, composer, conjoint, concerto; concours, comparer, consonne, confetti; complice, consacré, comptant, conjurer; farouche, fatiguer, fabrique, fabuleux; formelle, formuler, fortuite, forgeron; mâchoire, maritime, marraine, marabout; patronne, passager, passoire, patineur; parlante, partager, parterre, parfumer; précieux, préciser, prémices, prédicat; pression, préparer, pressing, préfacer; prochain, protéger, prodigue, profaner; prophète, procurer, prothèse, prohiber; radieuse, ramasser, rallonge, ratisser; réplique, résonner, réglisse, résident; reproche, retomber, retouche, repriser; richesse, ridicule, ripaille, ricaneur; supplice, susciter, suffrage, superflu; surprise, survivre, surplomb, surmener 


\section{APPENDIX B \\ Items Used In Experiment 2}

Items are listed in the following order: bisyllabic, trisyllabic.

barreste, barollet; badrique, badonage; battouse, badigron; barboche, barloter; béqueule, béchatel; béqualle, bénuvole; bilongue, bicolare; bislotte, bistoumi; bonnache, boviment; bougroir, boulipie; bouffane, boucrier; brouotte, brouhata; cannotte, cachalet; calarque cagosser; carrasse, cariplon; cervoite, certical; chetreau, chevaret; chiffler, chicater; cotieuse, codéreux; condoint, conlerto; confonne, condetti; corlaire, cortoran; courbare, courcatu; crachoin, cramonsi; faucelle, faumiler; garrague, galériet; gangrète, gangliot; grimotre, grimaler; jacanthe, jacassor; larmaire, larmoter; macraire, malotrée; mammoire, maraphon; maranne, maraner; margolle, margital; marmutte, martuler; marqueux, martipet; morphite, morbeler; mousseur, moucarde; nageoite, narratir; neipeuse, nénuthar; pagoille, patabole; passoite, patoneur; pastaque, pastorai; perriche, péfinois; perfreau, perfomer; pressine, préfunir; préfices, prélicat; prophèse, protiber; raflonge, ratageur; réflisse, résidene; risaille, ricaneux; sautisse, sauprenu; séguelle, sérépade; surtomme, surdager; tiglasse, titulant; triviole, tripolie, verblage, vercoulu; vergigne, verflacé; verteine, vertépré; vinnette, virulene

(Manuscript received July 7, 1998;

revision accepted for publication April 12, 1999.) 